\title{
Valuing Lake Erie Beaches Using Value and Function Transfers
}

\section{Leah H. Palm-Forster, Frank Lupi, and Min Chen}

\begin{abstract}
Two benefit-transfer approaches are used to estimate welfare losses from closure of Lake Erie beaches. We identify conditions for which the function transfer, which is more time-consuming and data-intensive, is worth the effort relative to a simple value transfer. The function transfer was essential for estimating beach demand (trips) and demand elasticity (change in trips); when evaluating individual beach closures with known trip demand, the two methods yielded similar results. Results produced by the two transfer methods deviated (up to 106 percent) when multiple beaches were closed simultaneously because value transfer did not account for the loss of beach substitutes.
\end{abstract}

Key Words: benefit function transfer, harmful algal blooms, random utility model, single-day trips, travel cost, value transfer

Benefit transfer is a valuation method in which values calculated for a resource in a primary study are used to estimate values for a similar resource at a different policy site. It is especially useful when answering urgent policy questions in situations in which constraints on time and/or money preclude the ability to collect primary data for the site in question because it allows researchers to respond quickly to a need for estimates of the value of the resource (Freeman, Herriges, and Kling 2014). One such site is the Western Lake Erie Basin, where beaches have had to be closed periodically in recent years because of harmful algal blooms (HABs) spurred primarily by phosphorus from agricultural run-off. The algae (Microcystis sp.) produce a toxin that is dangerous for humans, pets, and wildlife, and policymakers and stakeholders urgently need information regarding the causes and impacts of the blooms (International Joint Commission (IJC) 2014).

Leah H. Palm-Forster, Frank Lupi, and Min Chen are, respectively, assistant professor in the Department of Applied Economics and Statistics at University of Delaware; professor in the Department of Agricultural, Food, and Resource Economics at Michigan State University, and risk modeler, Internal Audit Division, Freddie Mac. Correspondence: Leah H. Palm-Forster = 206 Townsend Hall - 531 South College Avenue - Newark, DE 19716-2103 - Phone 302.831.1325 " Email leahhp@udel.edu.

We thank Li Cheng and Scott Knoche for assistance with data. We also thank Scott M. Swinton, participants in the 2015 Northeastern Agricultural and Resource Economics Association Water Quality Economics workshop, and two anonymous reviewers for insightful comments and suggestions. The lead author is appreciative of financial support from the National Science Foundation's Long-term Ecological Research Program (DEB 1027253) at the Kellogg Biological Station and funding from the Great Lakes Protection Fund through the Nature Conservancy. Support from Michigan State University's AgBioResearch is also appreciated.

The views expressed are the authors' and are not necessarily those of Freddie Mac, Freddie Mac's board of directors, or any of Freddie Mac's regulators.

Agricultural and Resource Economics Review 45/2 (August 2016) 270-292

(C) The Author(s) 2016. This is an Open Access article, distributed under the terms of the Creative

Commons Attribution licence (http://creativecommons.org/licenses/by/4.0/), which permits unrestricted re-use, distribution, and reproduction in any medium, provided the original work is properly cited. 
We apply two benefit-transfer methods-value transfer and function transfer-to estimate the value of Lake Erie's beaches and then analyze the relative merits of those methods when the availability of behavioral and economic data in the policy setting and the scale of the environmental damage being assessed (the number of beach sites closed) vary. When selecting a benefit-transfer method, researchers face a tradeoff between the simplicity of a value transfer and the ability of a function transfer to represent the unique characteristics of the policy site and the affected population more accurately. Our study contributes to an understanding of the relative advantages and disadvantages of each method for various policy environments.

The simplest method is value transfer, which involves assigning a single point estimate of value from a study site to a policy site. Value transfer is quick and straightforward but does not account for differences between the sites and assumes that the conditions of the study site are representative of the conditions of the policy site. So, for example, value transfer does not capture how choice sets differ. In the case of Lake Erie beaches, accounting for the availability of alternative beach sites is important-fewer sites in the choice set limit the substitute beaches available when some beaches are closed and can lead to substantial welfare losses.

Benefit function transfer is a more complex approach in which a value function estimated in one or more primary studies is used to value a resource at a different policy site (Boyle et al. 2010). Broadly speaking, function transfers are preferable to value transfers because they are more flexible and can account for heterogeneous population characteristics and amenity attributes (Kaul et al. 2013, Boyle et al. 2010, Johnston and Rosenberger 2010, Brouwer and Spaninks 1999). However, function transfers are more timeconsuming and require additional data about the policy site to calibrate the value function.

When conducting a benefit-transfer study, researchers must decide if the function transfer is worth the additional time and effort required. To evaluate the merit of the more complicated transfer method, we compare estimates of welfare losses from the closing of Lake Erie beaches using a value transfer and a function transfer. We estimate losses for single closures for each public Lake Erie beach site along the Michigan and Ohio coasts and for simultaneous regional closures of groups of beaches. Parsons et al. (2009) showed that group closures cause greater per-trip welfare losses than individual closures. In Lake Erie, bacterial contamination typically leads to one or a small number of beaches being closed while HABs typically affect much larger areas. We determine how the transfer method and number of beaches closed affect the value estimates in hypothetical closure scenarios.

We find that function transfer is preferred over value transfer to estimate trip demand when reliable data about trips are not available and to estimate welfare losses from regional closures. When transferring values from travel-cost models, our Lake Erie application shows that function transfer is essential for 
estimating beach demand (as trips) and demand elasticity (as change in trips). When the elasticity of trip demand is known and closures affect only a small number of beaches, the two methods produce similar results. Deviation between the estimates increases exponentially as the number of beaches closed increases. In addition, when conditions such as HABs significantly change the choice set of beaches, a benefit-function transfer is preferred since it more fully accounts for site-substitution effects and trip elasticity. If benefit function transfer is infeasible, identifying a study site with a comparable scale of beach closures to that of the policy site will facilitate a more applicable value transfer.

\section{Valuing Recreational Sites}

In the United States and Europe, government agencies commonly require completion of benefit-cost analyses to evaluate the potential impacts of proposed policies and management plans (Boyle et al. 2010, Johnston and Rosenberger 2010). Since constraints on time and funding often preclude the possibility of primary studies, the analyses often are based on benefit transfers. The use of transfer approaches dates back to the 1960s. In recent years, however, demand for more-reliable benefit-transfer methods has spurred development of more-sophisticated approaches (Brookshire and Neill 1992, Desvousges, Johnson, and Banzhaf 1998, Wilson and Hoehn 2006, Rolfe and Bennett 2006, Navrud and Ready 2007, Boyle et al. 2010, Johnston and Rosenberger 2010, Johnston et al. 2015) and identification of best practices in the form of a generally accepted protocol (Boyle et al. 2010).

Much of the research so far has focused on how to reduce transfer error: the difference between the true valuation of the policy resource and the valuation estimated using benefit transfer. The consensus from that research is that the study site and policy site should be as similar as possible in terms of populations, resources, markets, and site attributes and that function transfers are more accurate than value transfers (Boyle et al. 2010). However, some studies have suggested that function transfers do not always outperform value transfers (Barton 2002).

Both supply-side and demand-side factors affect the value of recreational amenities at study and policy sites (Freeman, Herriges, and Kling 2014). Supply-side factors include amenity characteristics such as onsite parking and the length of the beach while demand-side factors refer to characteristics of the people who value the resource, including their preferences and socioeconomic characteristics. The preference for function transfer is largely attributable to the flexibility it provides in accounting for heterogeneity in amenities and population characteristics, thus reducing transfer errors (Kaul et al. 2013, Rosenberger and Loomis 2003). However, the superior performance of function transfer relies on the assumption that the statistical relationships between independent and dependent variables used for the study site also apply to the policy site. Rosenberger and Loomis (2003) 
presented validity tests for thirteen benefit-transfer studies and reported that function transfer was generally more accurate than value transfer, though the range of errors under both approaches was considerable (Rosenberger and Loomis 2003, p. 458, table 6).

Another benefit of function transfer is the ability to predict public demand for trips to the recreation site when there is a lack of primary data. Deacon and Kolstad (2000) emphasized the importance of estimating beach visits in the absence of environmental disasters to determine the status-quo level of trip demand but noted that such records of visits are rarely available. ${ }^{1}$ They also stressed the importance of accounting for the availability of substitute sites since the presence (absence) of similar sites can decrease (increase) welfare losses when a beach is closed.

While use of function transfer and updated trip demand in behavioral models generally has been shown to reduce transfer error, the added value of incorporating more-complicated transfer approaches has varied. Zandersen, Termansen, and Jensen (2007), for example, transferred benefits of access to a recreational site over a twenty-year time horizon and showed that updating the demand for trips reduced transfer error by 282 percent on average compared to updating preferences only. Parsons and Kealy (1994) showed that estimates of recreation values from a function transfer came within 4 percent of the true values while the error rate for simple value transfers was 34 percent. They found that updated information about trip demand only minimally reduced the error rate for the value transfer.

\section{Lake Erie Beaches and Harmful Algal Blooms}

Spurred by excess phosphorus, a resurgence of eutrophication and HABs is threatening Lake Erie after a partial recovery in the mid-1990s (Johnson et al. 2014). The microcystin toxin produced from HABs harms ecosystems, contaminates drinking water supplies, forces closures of beaches, and reduces the value of fisheries, lakefront properties, and recreation sites. The largest recorded HAB in Lake Erie occurred in 2011 and drew international media attention (IJC 2014). In subsequent years, smaller persistent HAB events led to another expansive bloom in 2014 that contaminated drinking water sources for half a million people and triggered declaration of a state of emergency for three counties in the Toledo area.

In previous decades, the primary contributors of contaminants to Lake Erie were point sources such as factories and water treatment plants, but the more-recent events were caused by nutrients emitted from nonpoint sources such as agricultural production and lawns (IJC 2014) and involved thousands

\footnotetext{
1 Deacon and Kolstad (2000) highlighted the challenges associated with acquiring visitation data. When beaches have entry fees or controlled access points, estimating attendance can be relatively straightforward, but many beaches do not have such controls.
} 
of potential polluters (farmers and homeowners). Consequently, policies designed to limit such pollution are expensive and administratively challenging so it is important to understand the potential costs and benefits of a policy to determine whether it is economically worthwhile. In 2014, the federal government appropriated more than $\$ 2$ million in emergency funding to reduce run-off in the Western Lake Erie Basin through agricultural conservation programs that limit losses of phosphorus. The resulting influx of state, federal, and private spending has spurred stakeholders to demand timely information about the value of benefits generated by HAB mitigation programs.

Few studies have estimated recreation values for Lake Erie beaches, and an understanding of those values is essential for efforts to estimate the economic impacts of HABs accurately. In the mid-1990s, several studies examined select beach locations along the Ohio coast. Sohngen, Lichtkoppler, and Bielen (1999) studied two popular Lake Erie beaches, Maumee Bay State Park and Headlands Beach State Park, and estimated average values for single-day trips of $\$ 15.50$ for Headlands Beach and $\$ 25.50$ for Maumee Bay Beach in 1998 dollars. Using the same data set, Murray, Sohngen, and Pendleton (2001) examined the impact of beach advisories on welfare for fifteen Lake Erie beaches. They found that the average seasonal benefit of a reduction in seasonal advisories by one event was $\$ 28$ per visitor, which amounted to $\$ 3.2$ million per year for the fifteen beaches combined.

\section{Methods}

Benefit transfer allows us to estimate welfare losses from hypothetical beach closures in response to HABs at the policy site, the western and central basins of Lake Erie. We transfer beach values and apply an estimated benefit function from a study by Chen (2013) that valued Great Lakes beaches using a repeated random utility model and that explained Michigan residents' visits to beaches along the Michigan coast at Lakes Michigan, Huron, St. Clair, and Erie. We conduct the value transfer by predicting the number of displaced trips to Lake Erie beaches and multiplying that number by Chen's estimated average per-trip value. For our function transfer, we update Chen's repeated nested logit model with data on Lake Erie beach amenities and census tracts that characterize potential beach visitors from Michigan, Ohio, and Indiana.

Value transfers require estimates of trip demand and the elasticity of that demand, but current data on visits were not available for the majority of the Lake Erie beaches. We use Chen's model to generate predictions about the number of trips taken to each beach. The repeated random utility model can predict trip demand because it captures both site choices and participation decisions. And since the model was estimated for the entire adult population of Michigan, we can use it to predict the average number of trips for the population of the policy site. 
Chen's (2013) model is amenable to using census data for the function transfer. Using coefficients from the repeated nested logit model, we transfer the functions to estimate demand for single-day trips to Lake Erie beaches using population-weighted demographic data on potential beach users collected from five-year estimates in the 2012 American Community Survey (U.S. Census Bureau 2014). Our policy area encompasses 2,936 census tracts in Ohio, 1,702 census tracts in Michigan, and 102 census tracts in Indiana, and the universal choice set (the set of beaches that could have been visited by someone in the policy population) is comprised of 424 beaches located in Michigan and Ohio.

\section{The Random Utility Model}

We apply Chen's (2013) random utility model, which is illustrated in Figure 1. With a choice set of $J$ beaches, person $n$ will choose to visit beach $j$ on lake $k$ in choice occasion $t$ if that beach provides greater utility than all of the choice alternatives (other beaches), $i$ :

$$
U_{n j k t}>U_{n i k t}, \forall i \neq j, \forall k
$$

Utility consists of a deterministic portion, $V_{n j k t}$, that depends on observable characteristics, including the "price," and a random portion, $\varepsilon_{n j k t}$, that is not observed by the researcher:

$$
U_{n j k t}=V_{n j k t}+\varepsilon_{n j k t} .
$$

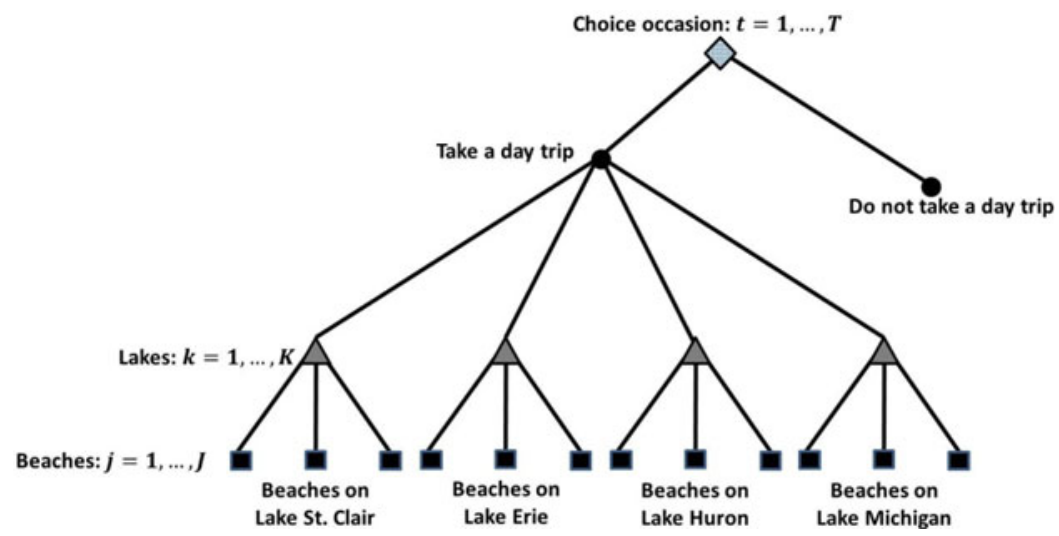

Figure 1. Structure of the Repeated Nested Logit Model 
In the model, $V_{n j k t}$ depends on the trip price (the travel cost) and the beaches' characteristics:

$$
\begin{aligned}
V_{n j k t}= & \beta_{p} \times \text { price }_{n j k}+\beta_{q} \times \text { beachquality }_{j k t} \\
= & \beta_{t c} \times \text { travelcost }_{n j k}+\beta_{l} \times \log \left(\text { beachlength }_{j k}\right)+\beta_{t} \times \text { temperature }_{j k t} \\
& +\beta_{c d} \times{\text { closuredays } 2010_{j k}+\beta_{r} \times \text { regionaldummies }_{j k} .}
\end{aligned}
$$

The $\beta$ parameters are presented in Table 1 . Table 1 also presents the demographic variables that were used to predict participation (i.e., taking a beach trip) using the repeated logit model (see Figure 1).

When the random portion of utility $\left(\varepsilon_{n j k t}\right)$ is independently and identically distributed as generalized extreme values, the probability that individual $n$ will choose beach $j$ on lake $k$ at time $t$ is given by a nested logit. In the repeated nested-logit model, the unconditional probability of person $n$ visiting beach $j$ on lake $k$ on day $t$ is

$$
\begin{aligned}
P_{n t}(j, k)= & P_{n t}(\text { trip }) P_{n t}(k \mid \text { trip }) P_{n t}(j \mid k, \text { trip }) \\
= & \frac{e^{\frac{V_{n j k t}}{\lambda}}\left(\sum_{l=1}^{J_{k}} e^{\frac{V_{n l k t}}{\lambda}}\right)^{\frac{\lambda}{\sigma}-1}\left(\sum _ { m = 1 } ^ { K } \left(\sum_{l=1}^{J_{m}} e^{\left.\left.\frac{V_{n l m t}}{\lambda}\right)^{\lambda / \sigma}\right)^{\sigma-1}}\right.\right.}{e^{V_{n t, n o t r i p}}+\left(\sum_{m=1}^{K}\left(\sum_{l=1}^{J_{m}} e^{\frac{V_{n l m t}}{\lambda}}\right)^{\lambda / \sigma}\right)^{\sigma}} .
\end{aligned}
$$

In this specification, $\lambda$ is the lake-level nesting parameter, $\sigma$ is the trip-level nesting parameter, and $\lambda$ measures the degree to which the beaches in a given nest are similar. Higher values of $\lambda$ indicate relatively less correlation (more independence) among the alternatives in the nest. The trip-level nesting parameter, $\sigma$, measures the degree to which the alternative of taking a beach trip differs from the choice not to take a beach trip.

\section{Predicting Trips}

We use Chen's (2013) model ${ }^{2}$ to predict the number of trips taken to each beach site during summer months (May 27 through September 30) in 2010 by residents

\footnotetext{
2 The choice probabilities, parameter estimates, and welfare measures reported in Chen (2013) contained a scaling error that we corrected for the present study. The re-estimated model and results for the Chen study are available from the authors. All references here are to the corrected model.
} 
in the policy area, which covers all of Ohio and parts of Michigan and Indiana. Since we do not have information about individuals or actual trips, we construct our observations using demographic characteristics for each census tract weighted by the number of adults in each census tract. We can thus predict the total number of day trips made to beach $j$ at lake $k$ in 2010 for each representative person $n$ :

$$
\begin{aligned}
\hat{Y}_{n}(j, k)= & \sum_{t=1}^{T} \hat{P}_{n t}(j, k) \\
= & \hat{P}_{n, \text { june }}(j, k) \times 35+\hat{P}_{n, \text { july }}(j, k) \times 31 \\
& +\hat{P}_{n, \text { aug }}(j, k) \times 31+\hat{P}_{n, \text { sept }}(j, k) \times 30 .
\end{aligned}
$$

We aggregate the daily trips into monthly figures because the average water temperature varies during the summer and influences visitors' utility and trips. Trips made the last five days of May are included in June, generating 35 choice occasions (potential beach days) in June, 31 in July, 31 in August, and 30 in September.

To calculate the total number of trips to beach $j$ at lake $k$, we multiply the trip estimates from equation 5 by the population of each census tract, $n$, and sum the census-tract estimates:

$$
\widehat{\operatorname{Trip}} s(j, k)=\sum_{n=1}^{N} \hat{Y}_{n}(j, k) \times \text { population }_{n} .
$$

We also predict how the number of trips to beach $j$ will change if one or more Lake Erie beaches closes.

$$
\Delta \widehat{\operatorname{Trip} s}(j, k)=\widehat{\operatorname{Trip}} s(j, k) \mid \text { status quo }-\widehat{\operatorname{Trip}} s(j, k) \mid \text { closure scenario }
$$

\section{Estimating Welfare Losses with Function Transfer}

Welfare loss from closure of one or more sites is calculated using the estimated parameters from the nested logit model specified by Chen (2013) in the inclusive value (IV) formula for each choice occasion (Haab and McConnell 2002):

$$
I V_{n t}=\ln \left(e^{V_{n t, n o t r i p}}+\left(\sum_{m=1}^{K}\left(\sum_{l=1}^{J_{m}} e^{\frac{V_{n l m t}}{\lambda}}\right)^{\lambda / \sigma}\right)^{\sigma}\right) .
$$

Over the entire season, an individual's inclusive value is the sum of the inclusive values in each choice occasion, $t$ : 


$$
\begin{aligned}
I V_{n} & =\sum_{t=1}^{T} I V_{n t} \\
& =I V_{n, \text { june }} \times 35+I V_{n, \text { july }} \times 31+I V_{n, \text { aug }} \times 31+I V_{n, \text { sept }} \times 30 .
\end{aligned}
$$

We determine individuals' willingness to pay (WTP) to avoid closures of one or more beach sites. The beach closure(s) may result in people choosing an alternative beach site or deciding not to go to the beach. To calculate this WTP, we subtract the expected maximum utility in the closure scenario $\left(I V_{n}^{1}\right)$ from expected maximum utility without the closure scenario $\left(I V_{n}^{0}\right)$ and divide by the negative of the estimated parameter of the travel cost, $\hat{\beta}_{t c}$. The total change in welfare is calculated by aggregating the individuals' WTP estimates from the function transfer $\left(\widehat{W T P}_{F T}\right)$. In equation 10, we multiply the WTP of a representative individual in census tract $n$ by the population of the census tract. Then, total WTP is calculated by summing the WTP values calculated for each of the 4,740 census tracts.

$$
\Delta \widehat{W}_{F T}=\widehat{W T P}_{F T}=\sum_{n=1}^{4,740} \frac{\left(I V_{n}^{0}-I V_{n}^{1}\right)}{-\hat{\beta}_{t c}} * \text { population }_{n}
$$

We calculate WTP per trip to a site by dividing the total WTP from equation 10 by the number of trips displaced (change in trips) from the site because of a closure, which was calculated in equation 7 :

$$
\widehat{W T P}_{F T, S}=\frac{\widehat{W T P}_{F T}}{\Delta \widehat{\operatorname{Trip}}_{S}} .
$$

In this formula, $S$ denotes the set of beaches closed. When a beach is closed, all trips to that beach are lost so the number of displaced trips equals the number of all trips to the site predicted under status-quo conditions (equation 6).

\section{Estimating Welfare Losses with Value Transfer}

Multiple approaches can be used to estimate aggregate welfare measures using value transfer; the most appropriate method depends on the availability of data about displaced trips. If the number of trips displaced is known (provided by an external source), the analyst can multiply the average WTP to avoid losing a trip by the number of displaced trips. Since we do not have such information, we predict the number of displaced trips using Chen's (2013) site-choice model. Total WTP to avoid the closure scenario is calculated by multiplying the change in predicted trips (equation 7) by the transferred per-trip WTP value: 


$$
\Delta \widehat{W}_{V T}=\widehat{W T P}_{V T}=\widetilde{\mathrm{WTP}} \text { per trip } \times \Delta \widehat{\operatorname{Trip}}_{S}
$$

where $\Delta \widehat{\operatorname{Trip}} S_{S}$ represents trips lost to site(s) $S$ that were closed. $\widetilde{\text { WTP }}$ is the pertrip WTP value estimated in the original study and transferred to the policy site.

This value transfer approach accounts for the popularity of each beach in terms of visits but does not account for differences in the number of choice alternatives or their quality. The number of choice alternatives in the original study and the policy site are quite different. Chen (2013) considered two southeast Michigan beaches in the Lake Erie nest while we consider two Michigan beaches and sixty-five Ohio beaches as substitutes in the same nest within the choice set. If we do not account for the additional alternatives available at the policy site, our model may overestimate the welfare loss incurred from closure of a typical Lake Erie beach because the relatively large number of alternatives in a nest allows individuals to avoid having to choose more-costly out-of-nest alternatives.

When trip data for the policy site are not available, the analyst can use aggregate welfare measures from the original study. In the context of our study, this would mean using the aggregate seasonal welfare losses estimated in Chen (2013). This approach accounts neither for the frequency of visits to the transfer site nor the availability of substitute sites. Another approach involves predicting displaced trips using a participation model, as we do in this study.

\section{Data}

\section{Travel Cost}

Both of the benefit-transfer methods employed in this study use the results from Chen's (2013) repeated nested logit to estimate welfare losses from hypothetical Lake Erie beach closures, but we do not limit the alternative choices to Lake Erie beaches. Our choice set consists of 357 beaches in the Lower Peninsula of Michigan along Lakes Michigan, Huron, and St. Clair and 67 Lake Erie beaches. All are public-access sites. The representative individuals' choice sets consist of beaches located within 250 miles of their residences ${ }^{3}$ since the probability of an individual making a single-day trip of more than 250 miles is low (Parsons and Hauber 1998). ${ }^{4}$ The choice set for the average census tract contains 162 sites.

To maintain consistency, we follow Chen (2013) and compute the travel cost by multiplying the round-trip driving distance by the average per-mile vehicleoperating cost ( $\$ 0.2422$ per mile) and adding the value of round-trip travel time at one-third of the household's income divided by 2,000 hours per year. The

\footnotetext{
3 In the model, the residence for each representative individual is located at the center of the individual's census tract.

4 Chen (2013) found that only 1 percent of people taking day trips visited a beach located more than 250 miles away, and Murray et al. (1999) reported that visitors traveled 53.5 miles on average for a single-day trip to a Lake Erie beach.
} 
Table 1. Estimated Parameters from the Repeated Nested Logit Model Used for the Function Transfer

\begin{tabular}{|c|c|c|}
\hline Variable & Estimate & t-Statistic \\
\hline \multicolumn{3}{|l|}{ Beach Level of Nested Logit Model } \\
\hline Travel cost & $-0.026^{* * *}$ & -82.61 \\
\hline Log(length) & $0.075^{* * *}$ & 22.47 \\
\hline Temperature & $0.033^{* * *}$ & 27.94 \\
\hline Closure days in 2010 & $-0.011^{* * *}$ & -22.42 \\
\hline Lower peninsula northeast & -0.031 & -0.53 \\
\hline Lower peninsula mideast & $-0.733^{* * *}$ & -12.01 \\
\hline Lower peninsula southeast & $-0.786^{* * *}$ & -12.67 \\
\hline Lower peninsula northwest & $0.745^{* * *}$ & 12.64 \\
\hline Lower peninsula midwest & $0.684^{* * *}$ & 11.31 \\
\hline Lower peninsula southwest & $0.339^{* * *}$ & 5.60 \\
\hline \multicolumn{3}{|l|}{ Lake Level of Nested Logit Model } \\
\hline Nesting parameter & $0.383^{* * *}$ & 68.87 \\
\hline \multicolumn{3}{|c|}{ Trip/No-trip Level of Nested Logit Model: No Trip } \\
\hline Nesting parameter & $0.536^{* * *}$ & 53.20 \\
\hline Male & $-0.124^{* * *}$ & -8.04 \\
\hline Age & $0.003^{* * *}$ & 4.43 \\
\hline White & $-0.056^{* *}$ & -2.32 \\
\hline Education years & $-0.105^{* * *}$ & -33.40 \\
\hline Full-time employed & $0.038^{* *}$ & 2.08 \\
\hline Retired & $0.187^{*}$ & 6.43 \\
\hline Children under seventeen years of age & $0.067^{* * *}$ & 3.84 \\
\hline Constant & $7.558^{* * *}$ & 62.89 \\
\hline
\end{tabular}

Note: * represents a 10 percent significance level, ${ }^{* *}$ represents a 5 percent significance level, and ${ }^{* * *}$ represents a 1 percent significance level.

Source: The corrected model based on Chen (2013) is available from the authors.

vehicle-operation cost per mile includes gasoline, maintenance, and tires plus per-mile depreciation as reported by the American Automobile Association (2011). It is important to note that Chen's calculation of marginal driving costs may be lower than the average driving cost used in other studies. ${ }^{5}$

5 Chen omitted the cost of insurance since it is a sunk cost that does not increase because of additional miles driven to a beach and computed the marginal depreciation rate by determining 
(a)

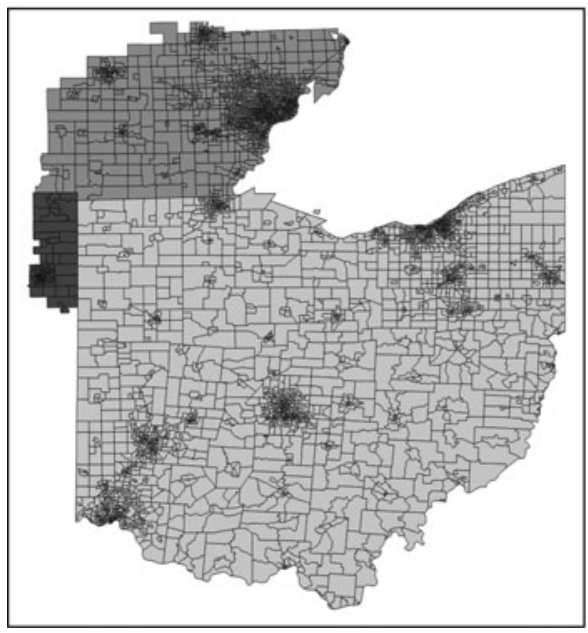

(b)

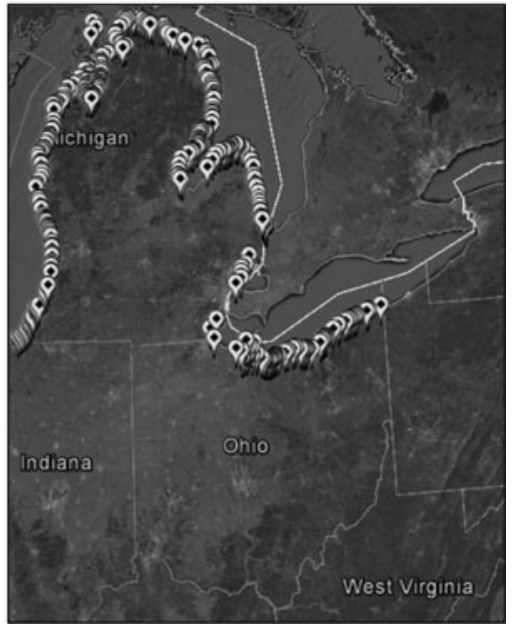

Figure 2. Location of the Census Tracts and Beaches

(a) Census tracts in Ohio, Michigan, and Indiana that reflect the policy site population.

(b) Great Lakes beaches in the universal choice set: 67 beaches along Lake Erie and 357 beaches along Lake Michigan and Lake Huron.

When comparing studies-and transferring values-it is important to consider the assumptions used in each study to compute travel costs, which can significantly affect the estimates of total welfare. We calculate the cost for average sedans, sport utility vehicles, and minivans. Chen computed a weighted average for Michigan vehicles by type based on a 2007 report by the Insurance Institute of Michigan that estimated the number of registered vehicles in the state. We assume that the distributions of car types in Michigan, Ohio, and Indiana are similar, thus allowing us to use the same estimated travel cost in all cases. To maintain consistency with the estimated parameters, we use the same 127 choice occasions as Chen: May 27 (Memorial Day weekend) through September 30, 2011.

\section{Demographic Data}

As shown in Figure 2a, the study area includes 2,936 census tracts in Ohio, 1,702 census tracts in Michigan east of Interstate 69, and 102 census tracts in Indiana east of Interstate 69 and north of Fort Wayne, Indiana. The people

how much the total depreciation cost increased when yearly miles driven increased from 10,000 to 15,000 and dividing the change in depreciation by 5,000 miles. Using the average depreciation cost would increase the driving cost by nearly 20 cents per mile. 
Table 2. Summary of Demographic Characteristics

\begin{tabular}{|c|c|c|c|c|c|}
\hline \multirow[b]{2}{*}{ Characteristic } & \multirow{2}{*}{$\begin{array}{c}\text { From Chen } \\
\text { Michigan } \\
\end{array}$} & \multicolumn{4}{|c|}{ Current Benefit-transfer Study } \\
\hline & & Ohio & Michigan & Indiana & Combined \\
\hline Total population eighteen or older & $7,561,510$ & $8,811,640$ & $7,561,510$ & $4,883,604$ & $21,256,754$ \\
\hline Sample used in study & $\begin{array}{l}6,375 \text { survey } \\
\text { respondents }\end{array}$ & $\begin{array}{l}2,936 \text { census } \\
\text { tracts }\end{array}$ & $\begin{array}{l}1,702 \text { census } \\
\text { tracts }\end{array}$ & $\begin{array}{l}102 \text { census } \\
\text { tracts }\end{array}$ & $\begin{array}{l}4740 \text { census } \\
\text { tracts }\end{array}$ \\
\hline People represented by census tracts & - & $8,803,060$ & $4,475,838$ & 284,035 & $13,562,933$ \\
\hline \multicolumn{6}{|c|}{ Demographic Characteristics of Sample Eighteen or Older } \\
\hline Age (mean) & 46.5 & 47.6 & 47.0 & 46.5 & 47.4 \\
\hline Income (mean in $\$ 1,000$ ) & 73,100 & 64,575 & 68,933 & 57,434 & 65,863 \\
\hline Education years (mean) & 14.4 & 13.5 & 13.8 & 13.3 & 13.6 \\
\hline Male (percent) & 48.6 & 48.0 & 47.8 & 48.3 & 48.0 \\
\hline White (percent) & 86.4 & 85.4 & 75.8 & 85.1 & 82.2 \\
\hline Employed full-time (percent) & 47.1 & 57.9 & 52.7 & 58.9 & 56.2 \\
\hline $\begin{array}{l}\text { Percent retired-proxy is percent } \\
\text { older than } 65\end{array}$ & 23.7 & 18.6 & 17.2 & 17.1 & 18.1 \\
\hline $\begin{array}{l}\text { Percent of children younger than } \\
\text { seventeen }\end{array}$ & 32.6 & 31.3 & 32.5 & 32.8 & 31.7 \\
\hline
\end{tabular}

Source: Chen (2013) and U.S. Census Bureau (2014). 
Table 3. Sources of Beach Data

\begin{tabular}{|c|c|c|}
\hline $\begin{array}{l}\text { Beach } \\
\text { Attribute }\end{array}$ & Description & Source \\
\hline Length & Length of beach in miles & $\begin{array}{l}\text { Ohio Department of Health 2014, } \\
\text { Michigan Department of } \\
\text { Environmental Quality 2014, } \\
\text { Google Earth } 2014\end{array}$ \\
\hline $\begin{array}{l}\text { Water } \\
\text { temperature }\end{array}$ & $\begin{array}{l}\text { Average monthly temperature of } \\
\text { surface water at points closest } \\
\text { to each beach }\end{array}$ & $\begin{array}{l}\text { National Oceanic and } \\
\text { Atmospheric Administration } \\
2014\end{array}$ \\
\hline Closure days & $\begin{array}{l}\text { Number of days that beach- } \\
\text { specific advisories were issued } \\
\text { in } 2010^{\text {a }}\end{array}$ & $\begin{array}{l}\text { Ohio Department of Health 2014, } \\
\text { Michigan Department of } \\
\text { Environmental Quality } 2014\end{array}$ \\
\hline \multirow[t]{2}{*}{$\begin{array}{l}\text { Regional } \\
\text { dummies }\end{array}$} & $\begin{array}{l}\text { Six binary variables that } \\
\text { indicated the region in which } \\
\text { the beach was located: } \\
\text { northwest, midwest, } \\
\text { southwest, northeast, mideast, } \\
\text { and southeast. }\end{array}$ & Chen 2013 \\
\hline & $\begin{array}{l}\text { Beaches in Ohio were assigned to } \\
\text { the southeast region. }\end{array}$ & \\
\hline
\end{tabular}

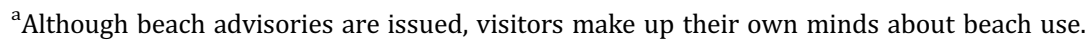

represented by these census tracts are relatively likely to visit Lake Erie beaches for day trips given their close proximity to the lake. We use the demographic attributes of each census tract to construct the observations, which are weighted by the population of the census tract so that the individual is representative of all residents in that area. The demographic data were collected from the 2008-2012 American Community Survey five-year estimates (U.S. Census Bureau 2014); Table 2 provides a summary of the population. The driving distances and travel times were computed using PC*Miler logistic mapping software to reflect miles and hours traveled on actual road networks between the center of each census tract and the 424 beaches in the universal choice set, which are depicted in Figure $2 b$.

\section{Beach Data}

Figure $2 \mathrm{~b}$ presents the location of the beaches in the universal choice set. Measured beach attributes are the length of the beach, the average water temperature, and the number of closure days in 2010. The data for these characteristics were obtained from a variety of publicly available sources that are described in Table 3.

Information about the presence of algal biomass would have allowed us to estimate welfare losses from marginal changes in water quality due to HABs. 
Unfortunately, we cannot connect the presence of algal bloom biomass to beach visits, but we can estimate welfare losses from the blooms using beach closures. Future studies could add value to this research by estimating marginal welfare losses from varying levels of algal biomass at beaches.

\section{Results}

\section{Predicting Trips}

We first use equation 4 to predict the probability of any individual making a single-day trip to beach $j$ at lake $k$ in choice occasion $t$ when no beaches are closed. We then use equation 5 to aggregate the probabilities of taking a single-day trip to beach $j$ at lake $k$ over all of the choice occasions to predict the seasonal number of single-day trips taken to beach $j$ at lake $k$ by each representative individual. By scaling those values up to the full population using equation 6 , we predict the total number of single-day trips taken to each beach during the summer season.

To evaluate the predictions, we compare them to previously reported estimates for beaches at Headlands State Park and Maumee Bay State Park, which is located fifteen miles east of Toledo and would be a prime candidate for a beach closure in the event of a HAB. ${ }^{6}$ Sohngen, Lichtkoppler, and Bielen (1999) reported approximately 238,000 visits to the beach at Maumee Bay State Park and 224,000 trips to the beach at Headlands State Park during summer months in 1998. Under normal (no HAB) conditions, our model predicts 269,352 day trips to Maumee (13 percent more) and 190,090 day trips to Headlands (15 percent fewer).

\section{Comparison of Transfer Approaches for Single-beach Closures}

We simulate 67 single-beach closures and use the seasonal inclusive values for the representative individuals from equation 9 to calculate WTP to avoid the loss of each beach site. Equation 10 estimates total WTP by all representative individuals to avoid lost trips due to a closure. We report three metrics: (i)

\footnotetext{
6 In its 2010 annual report, the Ohio Department of Natural Resources (ODNR) (2010) estimated the number of visitor occasions at East Harbor State Park, Headlands State Park, and Geneva State Park at 1.56 million, 4.37 million, and 730,000, respectively. Averaging across all of the park sites included in the report, we find that 9.5 percent of the visits were beach occasions. However, the estimates listed in the ODNR report did not account for the fact that some parks have no beaches while others are popular beach destinations. Furthermore, the report's estimates did not differentiate between single-day and multiple-day trips to a particular site. When we apply our rough assumption of 9.5 percent of trips being beach visits, we find approximately 148,200, 415,150, and 69,350 beach trips for East Harbor, Headlands, and Geneva State Parks respectively. Our model predicts 129,482, 190,090, and 69,076 singleday trips to the same beaches.
} 
WTP to avoid the loss of a single-day trip to each site (equation 11), (ii) welfare losses from closure of a beach for one day, and (iii) aggregate welfare losses from closure of a beach for the entire season.

Table 4 presents the resulting losses in welfare for seven of the single beach closures and compares the results from the value and function transfers. The value transfer uses the estimated WTP to avoid the loss of a single-day trip from Chen (2013): $\$ 18.08$ adjusted for inflation to reflect 2015 dollars using a consumer price index (U.S. Bureau of Labor Statistics 2015). ${ }^{7}$ The function transfer produces an average WTP of $\$ 15.91$ and per-beach WTP that is $2-12$ percent lower than WTP under Chen (2013). Overall, however, the estimates are similar.

Sohngen, Lichtkoppler, and Bielen's (1999) estimates for the beaches at Maumee Bay and Headlands State Parks were $\$ 25.60$ and $\$ 15.50$, respectively, per single-day trip-equivalent to $\$ 37.12$ and $\$ 22.48$ in 2015 dollars $^{8}$ (U.S. Bureau of Labor Statistics 2015). Using the benefit function transfer, we estimate per-trip values for those beaches of $\$ 16.39$ and $\$ 16.05$, respectively. Our considerably lower estimates are likely due in part to different assumptions regarding travel costs.

Table 4 also reports the results for a full-season closure of a beach. To estimate those welfare losses under the value transfer method, we use Chen's (2013) participation model to predict the number of visits in a season to each of the 67 beaches and then multiply that number by Chen's estimate of WTP per trip. The average full-season welfare losses per beach are $\$ 2.21$ million under value transfer and \$1.96 million under function transfer, a difference of 11 percent, and the deviations for the beaches are similar.

Overall, we find that the more-complicated function transfer provides no clear advantage over value transfer for evaluating welfare losses from closure of individual sites.

\section{Comparison of Transfer Approaches for Regional Beach Closures}

In the event of a $\mathrm{HAB}$, multiple beaches could be closed, and the impacts of such regional closures would likely be different from the impacts of closing a single beach since there would be fewer choice alternatives to use as substitutes. As the number of alternative beaches declines, we expect that fewer total trips will be taken, resulting in trips being permanently lost instead of displaced. We therefore simulate group closures and compare the estimates of welfare loss from such closures under value transfer and function transfer.

We consider closure of four groups of Lake Erie beaches: 2 Michigan beaches, 6 western Lake Erie beaches, all 33 western Lake Erie beaches, and all 67 Lake Erie beaches in Michigan and Ohio. The resulting estimates of welfare losses

$\$ 1.05(Y 2015)=\$ 1(Y 2011) \times 236 / 225$ (price index $2015 /$ price index 2011).

$8 \quad \$ 1.45(\mathrm{Y} 2015)=\$ 1(\mathrm{Y} 2011) \times 236 / 163$ (price index $2015 /$ price index 1998). 
Table 4. Welfare Losses for Selected Individual Beach Closure Scenarios

\begin{tabular}{|c|c|c|c|c|c|c|c|c|}
\hline \multirow[b]{3}{*}{ Beach Closed } & \multirow[b]{3}{*}{ State } & \multirow[b]{3}{*}{$\begin{array}{c}\text { Basin } \\
\text { Region }\end{array}$} & \multicolumn{3}{|c|}{ Per-trip-to-site Loss } & \multicolumn{3}{|c|}{ Aggregate Seasonal Loss } \\
\hline & & & \multicolumn{3}{|c|}{2015 Dollars } & \multicolumn{3}{|c|}{ Million 2015 Dollars } \\
\hline & & & $\begin{array}{c}\text { Value } \\
\text { Transfer }\end{array}$ & $\begin{array}{l}\text { Function } \\
\text { Transfer }\end{array}$ & $\begin{array}{c}\text { Percent } \\
\text { Deviation }\end{array}$ & $\begin{array}{c}\text { Value } \\
\text { Transfer }\end{array}$ & $\begin{array}{l}\text { Function } \\
\text { Transfer }\end{array}$ & $\begin{array}{c}\text { Percent } \\
\text { Deviation }\end{array}$ \\
\hline Sterling State Park & Michigan & Western & 18.08 & 17.77 & -1.7 & 12.32 & 12.11 & -1.7 \\
\hline Luna Pier City Beach & Michigan & Western & 18.08 & 16.44 & -9.1 & 5.93 & 5.39 & -9.1 \\
\hline Maumee Bay State Park & Ohio & Western & 18.08 & 16.39 & -9.3 & 4.87 & 4.42 & -9.3 \\
\hline East Harbor State Park & Ohio & Western & 18.08 & 15.90 & -12.1 & 2.34 & 2.06 & -12.1 \\
\hline Headlands State Park & Ohio & Central & 18.08 & 16.05 & -11.2 & 3.44 & 3.05 & -11.2 \\
\hline Geneva State Park & Ohio & Central & 18.08 & 15.95 & -11.8 & 1.25 & 1.10 & -11.8 \\
\hline Lakeshore Park & Ohio & Central & 18.08 & 15.87 & -12.2 & 0.50 & 0.44 & -12.2 \\
\hline Average western basin & - & Western & 18.08 & 15.92 & -12.0 & 2.21 & 1.99 & -10.1 \\
\hline Average central basin & - & Central & 18.08 & 15.91 & -12.0 & 2.20 & 1.94 & -11.9 \\
\hline Average Lake Erie & - & - & 18.08 & 15.91 & -12.0 & 2.21 & 1.96 & -11.0 \\
\hline
\end{tabular}

Notes: The per-trip-to-site function transfer was computed using equation 11 . The value transfer for the aggregate seasonal loss was computed using equation 12, and the function transfer was computed using equation 10. 2015 dollars were computed as $\$ 1.05$ (Y2015) = \$1(Y2011) × 236/225 (Price Index 2015 / Price Index 2011) (U.S. Bureau of Labor Statistics 2015). 
Table 5. Welfare Losses for Selected Regional Beach Closure Scenarios

\begin{tabular}{|c|c|c|c|c|c|c|c|c|}
\hline \multirow[b]{2}{*}{ Closed Beaches } & \multicolumn{4}{|c|}{ Per-site-trip Loss in 2015 Dollars } & \multicolumn{4}{|c|}{ Aggregate Loss per Day in Thousand 2015 Dollars } \\
\hline & $\begin{array}{c}\text { Value } \\
\text { Transfer }\end{array}$ & $\begin{array}{l}\text { Function } \\
\text { Transfer }\end{array}$ & $\begin{array}{c}\text { Function } \\
\text { Transfer } \\
95 \text { Percent } \\
\text { Confidence } \\
\text { Interval }\end{array}$ & $\begin{array}{c}\text { Percent } \\
\text { Deviation }\end{array}$ & $\begin{array}{c}\text { Value } \\
\text { Transfer } \\
\end{array}$ & $\begin{array}{l}\text { Function } \\
\text { Transfer }\end{array}$ & $\begin{array}{c}\text { Function } \\
\text { Transfer } \\
95 \text { Percent } \\
\text { Confidence } \\
\text { Interval } \\
\end{array}$ & $\begin{array}{c}\text { Percent } \\
\text { Deviation }\end{array}$ \\
\hline 2 Michigan beaches & 18.08 & 19.01 & {$[13.98 ; 23.13]$} & 5.1 & 143.69 & 151.09 & [111.09; 183.85] & 5.1 \\
\hline 6 western basin beaches & 18.08 & 20.12 & {$[18.88 ; 21.64]$} & 11.3 & 233.45 & 259.78 & {$[192.05 ; 324.50]$} & 11.3 \\
\hline 33 western basin beaches & 18.08 & 23.46 & {$[21.78 ; 25.50]$} & 29.7 & 573.73 & 744.32 & {$[547.40 ; 1,011.38]$} & 29.7 \\
\hline 67 Lake Erie beaches & 18.08 & 37.21 & {$[33.61 ; 42.73]$} & 105.8 & $1,163.60$ & $2,394.38$ & {$[1,808.46 ; 3,109.35]$} & 105.8 \\
\hline
\end{tabular}

Notes: The per-site-trip function transfer was computed using equation 11 . The value transfer for the aggregate loss per day was computed using equation 12 , and the function transfer was computed using equation 10. 2015 dollars were computed as $\$ 1.05$ (Y2015) $=\$ 1$ (Y2011) $\times 236 / 225$ (Price Index $2015 /$ Price Index 2011) (U.S. Bureau of Labor Statistics 2015). 


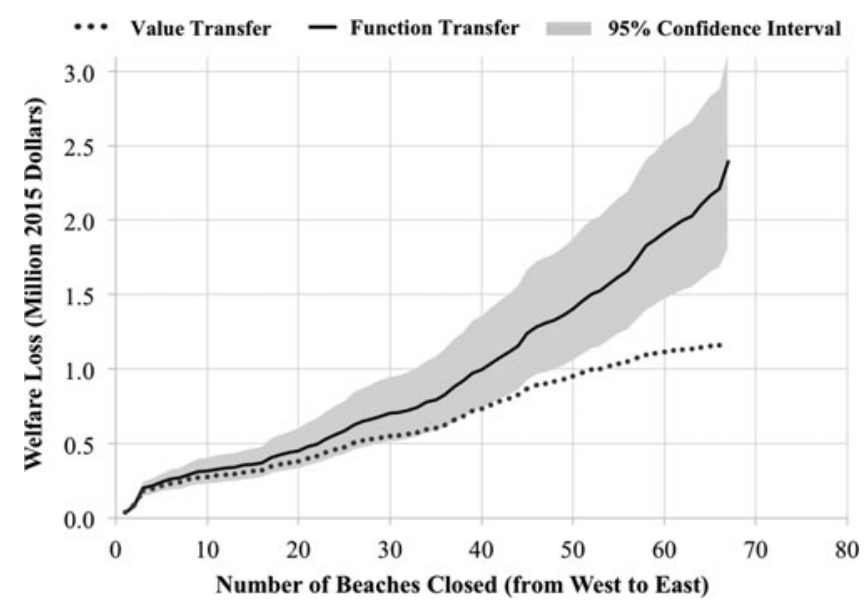

Figure 3. Comparison of Estimated Daily Welfare Losses for Simultaneous Single-day Beach Closures

from value and function transfers are presented in Table 5. We find much greater deviation between estimates generated by value and function transfers when groups of beaches are closed relative to single-beach closures. Furthermore, the value transfer approach, which predicted larger welfare losses than the function approach for individual closures, predicts significantly smaller welfare losses than the function approach for regional closures. The amount of deviation between the welfare estimates increases as the number of beaches closed rises. We find that the welfare losses estimated using function transfer are up to 106 percent greater than the estimates calculated with value transfer.

To further examine the scenario in which all 67 beaches are closed, we consider a case in which a bloom originates at the westernmost point of Lake Erie and spreads eastward, causing a sequential closing of beaches from west to east. Figure 3 presents the results of our estimates of the daily welfare losses for single-day closures, which increase exponentially with each additional beach closed, and 95-percent confidence intervals for the values from the function transfer constructed using 120 sets of beta coefficients estimated by bootstrapping the model from the original study.

\section{Conclusions and Discussion}

Benefit transfers are often viewed as simpler and more cost-effective alternatives to conducting primary valuation studies, but they require considerable care and careful analysis to obtain reliable value estimates. We use relatively simple value transfers and more time-consuming and data-intensive function transfers to 
estimate welfare losses generated by closures of Lake Erie beaches and compare those estimates for both individual and regional beach closures. Our primary goal is to identify conditions under which the more time-consuming and data-intensive function transfer is worth the effort. Several prior studies (Parsons and Kealy 1994, Zandersen, Termansen, and Jensen 2007, Deacon and Kolstad 2000) have shown that the degree of transfer error for visits to recreational sites can be reduced by incorporating information about demand for trips and the set of trip substitutions available, but such behavioral information generally is not readily available and can be expensive and/or time-consuming to acquire.

Function transfers are preferable when demand for trips to the policy site is not well documented, as is the case for our study area. Of the 67 beaches included in our study, current data on demand for trips were available for only four and no data were available on sites used as substitutes or on the elasticity of trip demand. Transferring values from Chen's (2013) model allowed us to estimate the number of trips to Lake Erie beaches taken by residents of Ohio, Michigan, and Indiana and the individual sites visited under normal conditions when no beaches were closed. We then evaluated how trip demand changed and how much value would be lost under various beach-closure scenarios.

Our results suggest that the value and function transfer approaches yield nearly the same welfare estimates when considering closure of a single beach. However, the deviation in the two approaches' estimates increases exponentially as the number of beaches closed gets larger. In the case of regional closures, value transfer yields substantially lower welfare estimates than function transfer. The differences in the estimates from our value and function transfers are moderate because of the significant similarity between the primary and policy sites, but we show that deviation between the estimates increases significantly with the scale of closures. Benefit-transfer studies in which the primary and policy sites are less similar may find even larger differences in response to the scale of closures. We therefore conclude that function transfer is preferable when estimating welfare losses from beach closures at multiple scales.

Because we lack the data needed to estimate the "true" value of beach access, it is difficult to determine which model performs "best," but economic intuition points to two important benefits of using function transfer to estimate welfare losses from regional closures. First, by reflecting the price elasticity of the demand for trips, function transfer accounts for displaced (to substitute sites) and lost trips. Second, estimates of trip substitution better reflect the choice set of the policy site, which can be substantially different from the choice set of the primary study site. We also find that estimates from a value transfer are more accurate when the scales of beach closures at the primary study and policy sites are similar.

Lack of data resulted in several limitations. We are not able to estimate welfare losses from the presence of algal biomass at beaches that remained 
open or the persistence of welfare losses after beaches reopen caused by degraded beach conditions (Deacon and Kolstad 2000). In addition, stigma associated with the poor quality of the beach can remain long after the beach is restored. Deacon and Kolstad (2000) referred to this as the "perceptually degraded period." Those welfare effects cannot be measured without data on how visits to the beach changed in response to a bloom that occurred months or years earlier. Future research on the long-term welfare impacts of HABs could make an important contribution to the literature, particularly if the studies could show how the value of the beaches changed specifically because of the HABs as opposed to other causes of beach degradation and closure.

Availability of a recent, well-documented study valuing Great Lakes beaches (Chen 2013) was an asset for our analysis. We recognize that researchers rarely find studies that are as amenable to benefit transfer between a study and policy site. Part of the value of Chen's (2013) research for function transfer is that it is a full-population model that can be readily transferred to other regions using census data. We conclude by highlighting three ways researchers can increase the usefulness of primary valuation studies to make the results more amenable to transfer.

The first is reporting useful value metrics that can be easily transferred to policy sites. Parsons et al. (2009), for example, calculated a loss-to-trips ratio that is easily transferred to other sites. It is also essential to report information about the choice sets used in the study so that characteristics of the alternatives in the study and policy sites can be compared. The size of the choice set and the attributes of site alternatives have an impact on welfare values, especially when evaluating regional resource changes.

The second recommendation is to report valuations for multiple scales of impact (e.g., single sites versus regions). A range of resource valuations will facilitate transfers when the scales of impact for the study and policy sites are different.

Finally, we recommend estimating models that can be used to generate demand for trips at future policy sites because information about displaced trips is often unavailable, unreliable, or outdated. In the context of randomutility-model travel-cost studies, visitors' participation can be included to understand the population who uses the recreational amenity. Since Chen (2013) used a population-wide survey to identify beach users, she could scale up the beach values to represent the entire Michigan population, and that allowed us to use a function transfer based on census data from other policy areas. Much of the work on benefit transfers has addressed valuation. An often-overlooked advantage of function transfer is the ability to generate trip estimates when data on trips for the policy site are either lacking or inadequate. 


\section{References}

American Automobile Association. 2011. "Your Driving Costs." Available at http://newsroom. aaa.com/wp-content/uploads/2011/08/YourDrivingCosts2011.pdf (accessed February 2014).

Barton, D.N. 2002. "The Transferability of Benefit Transfer: Contingent Valuation of Water Quality Improvements in Costa Rica." Ecological Economics 42(1/2): 147-164.

Boyle, K.J., N.V. Kuminoff, C.F. Parmeter, and J.C. Pope. 2010. "The Benefit-transfer Challenges." Annual Review of Resource Economics 2(1): 161-182.

Brookshire, D.S., and H.R. Neill. 1992. "Benefit Transfers: Conceptual and Empirical Issues." Water Resources Research 28(3): 651-655.

Brouwer, R., and F.A. Spaninks. 1999. "The Validity of Environmental Benefits Transfer: Further Empirical Testing." Environmental and Resource Economics 14(1): 95-117.

Chen, M. 2013. "Valuation of Public Great Lakes Beaches in Michigan." Ph.D. dissertation, Michigan State University, East Lansing. Available at http://web2.msue.msu.edu/ afreTheses/fulltext/Min\%20Chen\%20Dissertation.pdf (accessed May 31, 2015).

Deacon, R.T., and C.D. Kolstad. 2000. "Valuing Beach Recreation Lost in Environmental Accidents." Journal of Water Resources Planning and Management 126(6): 374-381.

Desvousges, W.H., F.R. Johnson, and H.S. Banzhaf. 1998. Environmental Policy Analysis with Limited Information: Principles and Applications of the Transfer Method. Cheltenham, UK: Edward Elgar Publishing.

Freeman, A.M.I., J.A. Herriges, and C. Kling. 2014. The Measurement of Environmental and Resource Values: Theory and Methods. Florence, KY: Routledge.

Google, Inc. 2014. Google Earth software, version 7.1.5.1557. Mountain View, CA: Google Inc. Available at www.google.com/earth (accessed February 2014).

Haab, T.C., and K.E. McConnell. 2002. Valuing Environmental and Natural Resources: The Econometrics of Non-Market Valuation. Cheltenham, UK: Edward Elgar Publishing.

International Joint Commission. 2014. "A Balanced Diet for Lake Erie: Reducing Phosphorus Loadings and Harmful Algal Blooms, A Report of the Lake Erie Ecosystem Priority." Available at www.ijc.org/files/publications/2014\%20IJC\%20LEEP\%20REPORT.pdf (accessed March 25, 2014).

Johnson, L.T., D.B. Baker, R.B. Confesor, K.A. Krieger, and R.P. Richards. 2014. "Research to Help Lake Erie: Proceedings of the 'Phosphorus along the Land-River-Lake Continuum' Research Planning and Coordination Workshop." Journal of Great Lakes Research 40 (3): 574-577.

Johnston, R., J. Rolfe, R. Rosenberger, and R. Brouwer (eds). 2015. Benefit Transfer of Environmental and Resource Values: A Guide for Researchers and Practitioners. New York, NY: Springer.

Johnston, R.J., and R.S. Rosenberger. 2010. "Methods, Trends and Controversies in Contemporary Benefit Transfer." Journal of Economic Surveys 24(3): 479-510.

Kaul, S., K.J. Boyle, N.V. Kuminoff, C.F. Parmeter, and J.C. Pope. 2013. "What Can We Learn from Benefit Transfer Errors? Evidence from Twenty Years of Research on Convergent Validity." Journal of Environmental Economics and Management 66(1): 90-104.

Michigan Department of Environmental Quality. 2014. "Michigan BeachGuard System." Michigan Department of Environmental Quality, Lansing, MI. Available at www.deq. state. mi.us/beach (accessed September 22, 2014).

Murray, C., B. Sohngen, F. Lichtkoppler, and M. Bielen. 1999. "Economics of Lake Erie Beaches: 1998 Lake Erie Beach User Survey Results." FS-082, Ohio Sea Grant College Program, Columbus, OH. Available at http://nsgl.gso.uri.edu/ohsu/ohsug99003.pdf (accessed September 9, 2014).

Murray, C., B. Sohngen, and L. Pendleton. 2001. "Valuing Water Quality Advisories and Beach Amenities in the Great Lakes.” Water Resources Research 37(10): 2583-2590. 
Navrud, S., and R. Ready (eds). 2007. Environmental Value Transfer: Issues and Methods. Dordrecht, The Netherlands: Springer.

National Oceanic and Atmospheric Administration, Great Lakes Environmental Research Laboratory. 2014. "Unpublished data, Great Lakes Coastal Forecasting System." Available at www.glerl.noaa.gov (accessed June 1, 2015).

Ohio Department of Health. 2014. "Ohio BeachGuard System." Ohio Department of Health, Columbus, OH. Available at www.odh.ohio.gov/healthybeaches (accessed September 22, 2014).

Ohio Department of Natural Resources. 2010. “Ohio State Parks 2010 Annual Report.” 2010. ODNR, Columbus, OH. Available at http://parks.ohiodnr.gov/portals/parks/pdfs/about/ 2010-annual-report.pdf.

Parsons, G.R., and A.B. Hauber. 1998. "Spatial Boundaries and Choice Set Definition in a Random Utility Model of Recreation Demand." Land Economics 74(1): 32-48.

Parsons, G.R., A.K. Kang, C.G. Leggett, and K.J. Boyle. 2009. "Valuing Beach Closures on the Padre Island National Seashore." Marine Resource Economics 24(3): 213-235.

Parsons, G.R., and M.J. Kealy. 1994. "Benefits Transfer in a Random Utility Model of Recreation." Water Resources Research 30(8): 2477-2484.

Rolfe, J., and J. Bennett. 2006. Choice Modelling and the Transfer of Environmental Values. Cheltenham, UK: Edward Elgar Publishing.

Rosenberger, R.S., and J.B. Loomis. 2003. "Benefit Transfer." In P.A. Champ, K.J. Boyle, and T.C. Brown, eds., A Primer on Nonmarket Valuation: The Economics of Non-Market Goods and Resources. Dordrecht, The Netherlands: Springer.

Sohngen, B., F. Lichtkoppler, and M. Bielen. 1999. "The Value of Lake Erie Beaches." FS-078, Ohio Sea Grant College Program, Columbus, OH. Available at http://nsgl.gso.uri.edu/ ohsu/ohsug99003.pdf (accessed September 9, 2014).

U.S. Bureau of Labor Statistics. 2015. "Consumer Price Index All Urban Consumers (CPI-U) U.S. City Average All Items." Archived Consumer Price Index Detailed Report Information. Available at www.bls.gov/regions/midwest/data/consumerpriceindexhistorical_us_table. pdf (accessed July 2015).

U.S. Census Bureau. 2014. "American Community Survey Five-year Estimates (2008-2012); American FactFinder." U.S. Census Bureau, Washington, DC. Available at http:// factfinder.census.gov (accessed February 12014 ).

Wilson, M.A., and J.P. Hoehn. 2006. "Valuing Environmental Goods and Services Using Benefit Transfer: The State of the Art and Science." Ecological Economics 60(2): 335-342.

Zandersen, M., M. Termansen, and F.S. Jensen. 2007. "Testing Benefits Transfer of Forest Recreation Values over a Twenty-year Time Horizon." Land Economics 83(3): 412-440. 